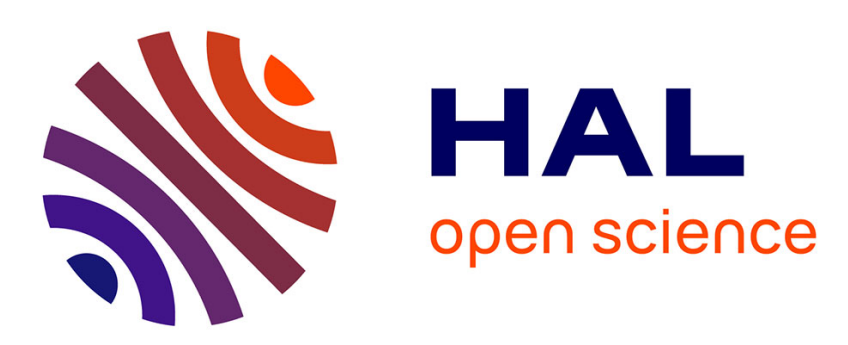

\title{
Numerical modelling of clip manufacturing: focus on the heat treatment
}

\author{
Richard Spataro, François Bay, Yvan Chastel, Florian Herrbach
}

\section{To cite this version:}

Richard Spataro, François Bay, Yvan Chastel, Florian Herrbach. Numerical modelling of clip manufacturing: focus on the heat treatment. 11th ESAFORM Conference on Material Forming, Apr 2008, Lyon, France. pp.Pages 1051-1054, 10.1007/s12289-008-0199-5 . hal-00510357

\section{HAL Id: hal-00510357}

https://hal-mines-paristech.archives-ouvertes.fr/hal-00510357

Submitted on 18 Aug 2010

HAL is a multi-disciplinary open access archive for the deposit and dissemination of scientific research documents, whether they are published or not. The documents may come from teaching and research institutions in France or abroad, or from public or private research centers.
L'archive ouverte pluridisciplinaire HAL, est destinée au dépôt et à la diffusion de documents scientifiques de niveau recherche, publiés ou non, émanant des établissements d'enseignement et de recherche français ou étrangers, des laboratoires publics ou privés. 


\title{
Numerical modelling of clip manufacturing: focus on the heat treatment
}

\author{
R. SPATARO ${ }^{1}$, François Bay ${ }^{2}$, Yvan Chastel $^{2}$, Florian Herrbach ${ }^{2}$ \\ ${ }^{1}$ CETIM (Centre Technique des Industries Mécaniques) - 7, rue de la Presse, BP 802, 42952 Saint Etienne \\ Cedex 9, France \\ URL: $\underline{\text { www.cetim.fr }}$ \\ e-mail: richard.spataro@cetim.fr
}

${ }^{2}$ CEMEF (Centre de Mise en Forme des Matériaux), Ecole des Mines de Paris, 06904 Sophia Antipolis, France

URL: www.cemef.com

e-mail:yvan.chastel@ensmp.fr; francois.bayl@ensmp.fr

ABSTRACT: Nowadays, manufacturers of clips have to face dimensional problems of their products which are heat treated. By using the numerical approach, companies want to understand reasons of these deformations. Thanks to the modelling of the shaping operation, we obtain the shape and residual stresses of the clip ready for heat treatment. After to have identify thermomecanic parameters used by FORGE2005 ${ }^{\circledR}$ TTT on a specific test bench called TABOO, we study the quenching and heating operations. We can so notice that geometrical evolutions are mainly due to residual stresses of bending.

Key words: distortions, quenching, heat treatment, residual stresses, clip, FORGE ${ }^{\circledR} 2005$

\section{INTRODUCTION}

The clipping companies' main preoccupation today is to meet the European dimensional requirements. And when these cutting and bending parts are heat treated, it becomes very uncertain... Nowadays, distortions due to the heat treatment are not totally controlled and then manufacturers have to multiplicate industrial tests to get the right part. We can see some samples of clips on the following figure 1.

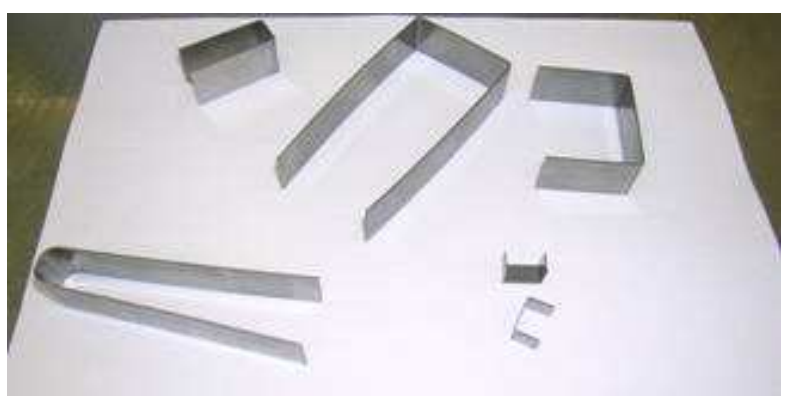

Fig. 1. Example of clips

CETIM done a first experimental study, but even if a lot of clips were produced with industrial conditions, no conception rule or predictive law could be determined. We only are able to notice the great influence of heat treatment on the final geometries.
According to these experimental results, manufacturers and the CETIM want to lean on numerical simulation. Through the model of one part, the goal is to detect and quantify the heat treatment effects on the final shape of the clip.

\section{INDUSTRIAL CONTEXT}

\subsection{The cycle of clip manufacturing}

We can distinguish two main steps in the clip manufacturing. The first one consists in the shaping of parts through mainly a bending operation. The second is characterized by a heat treatment divided into two stages, the heating and the quenching. We can represent the clip manufacturing by the following figure 2 :

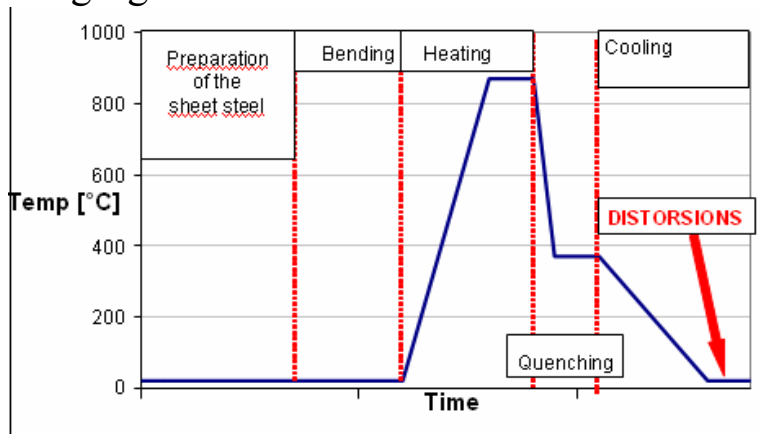

Fig. 2. Manufacturing cycle of clip 


\subsection{Distortions}

The objective of this study is to observe and to quantify the shape distortions, modifying the global geometry of the clip. During heat treatment, great distortions can appear. They result from interactions between the mechanical, thermal and metallurgical phenomena.

In our case, the distortions observed on clip concern with the variation of the distance $\mathrm{d} 2$ between both legs of the clip, as we can see on the figure 3 .

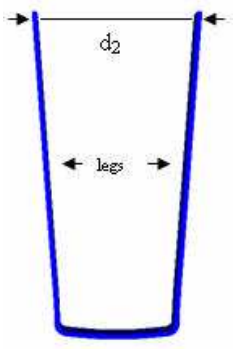

Fig. 3. Clip's distortion

\section{OPERATION OF SHAPING}

\subsection{Experimental approach}

The material use for this study is a XC68 steel. The tool use for the bending is illustrated on figure 4

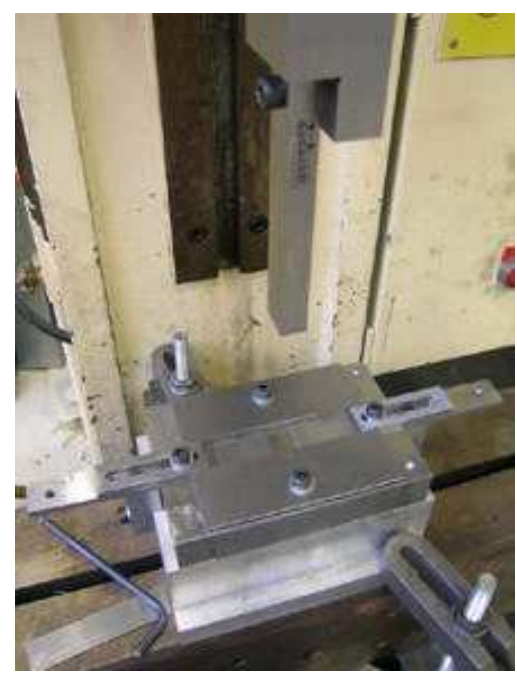

Fig. 4. bending die

We distinguish two main elements: the header die punch which is piloting in movement, so as to come to stamp the initial test sheet metal; the lower die, fixed to a support.

These tests of bending allowed us to obtain mainly measures of curves strength vs movement. These results could be comparing to numerical results.

\subsection{Modelling}

The simulation of the bending was not the priority of the study, based essentially on the analysis of the heat treatment effects.

The objective is only to obtain the global shape of the clip and the approximate distribution of the residual stresses.

As all the simulations of this study, we use the FORGE $^{\circledR} 2005$ software.

This model takes into account the forming, the exit of the clip to the lower die and the spring-back.

The numerical curves effort-movement are in concordance with experimental results and so we can approve the simulation.

On the following figure 5 we can notice the final shape and the residual stresses repartition:

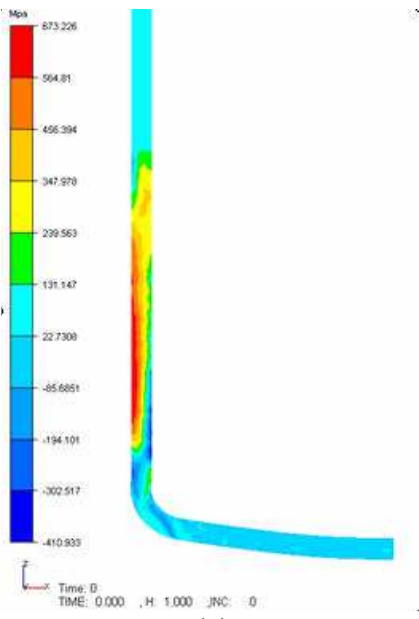

(a)

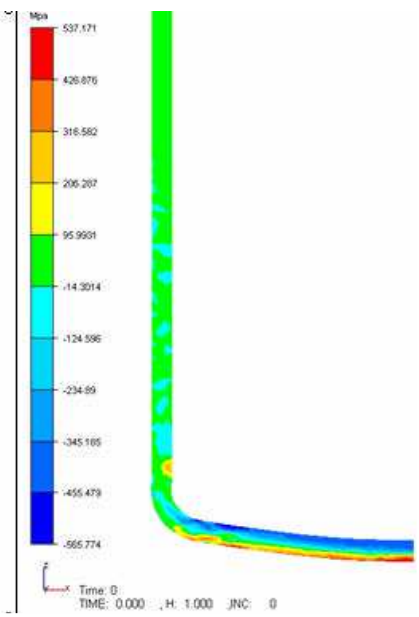

(b)
Fig. 5. Residual stresses: $\sigma_{\mathrm{xx}}(\mathrm{a}) ;: \sigma_{\mathrm{zz}}$ (b)

Through this study, the influence of main parameters, like friction or strain hardening law, has been revealed too. So we track down several points to study again for a future better modelling of the bending operation (floating tools, strain hardening kinematics, etc...).

\section{HEAT TREATMENT}

\subsection{Characterisation tests}

For modelling the behaviour of our part during the heat treatment, we use the FORGE $^{\circledR} 2005$ TTT software and so we have to identify material parameters.

The laboratory of the CEMEF develops a specific test called TABOO. This is a machine of mini stretching with heating by Joule effect. 
The following figure 6 shows TABOO :

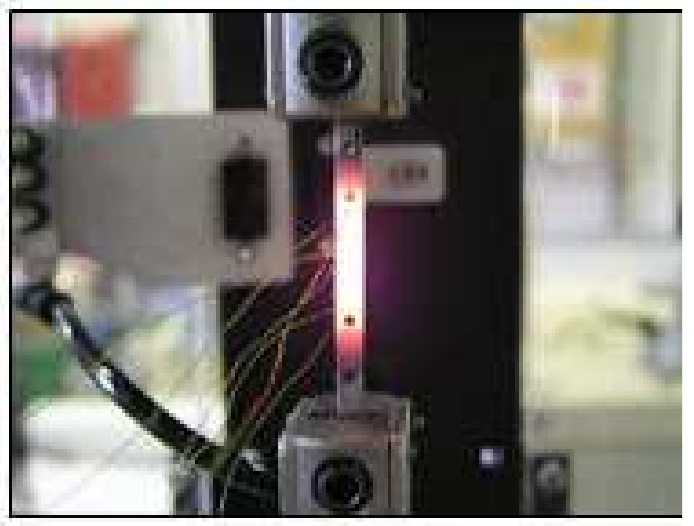

Fig. 6. TABOO test

The rheological law used by FORGE ${ }^{\circledR} 2005$ TTT is the following one:

$$
\sigma=\sigma_{0}+H \bar{\varepsilon}^{n}+K \dot{\bar{\varepsilon}}^{m}
$$

Where: $\sigma o=$ yield strength $(\mathrm{MPa}), H=$ hardening modulus (MPa), $n=$ hardening coefficient, $K=$ viscosity function (MPa.s ${ }^{-\mathrm{m}}$ ), $m$ strain rate sensitivity index

Several tests are done under different temperatures or different strain rates, in order to identify the plastic behaviour of our material. According to the curves shown in figure 7 , we can determine parameters necessary for the simulation of the heat treatment.

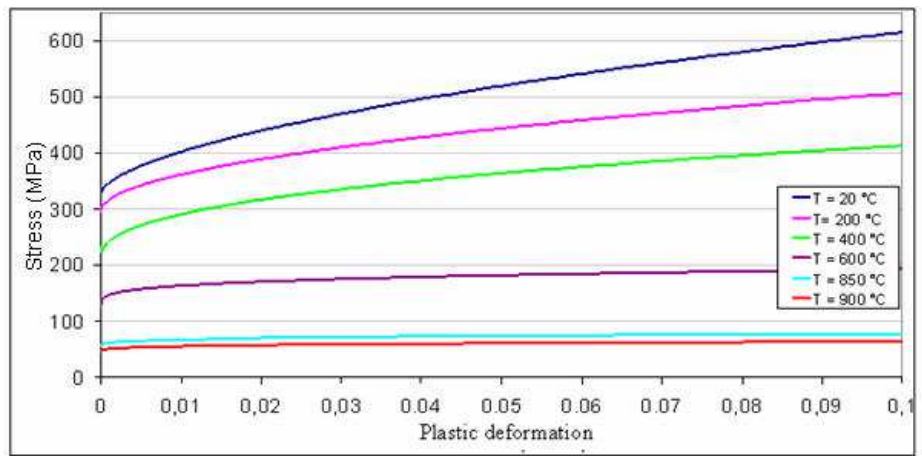

Fig. 7. Evolution of the law according to the temperature

$$
\left(\dot{\bar{\varepsilon}}=0,01 s^{-1}\right)
$$

\subsection{Modellisation of quenching}

The initial geometry of the clip used for the quenching simulation, is the one obtained at the end of the study of bending.

We simulate a quenching of $5 \mathrm{~min}$ to $370{ }^{\circ} \mathrm{C}$. The initial temperature of quenching is about to $870^{\circ} \mathrm{C}$, the final temperature of heating. After a long holding at this temperature we can suppose that the initial phase of the material for quenching is only austenitic.

On the following figure 8 we notice the displacement of three clip's points:

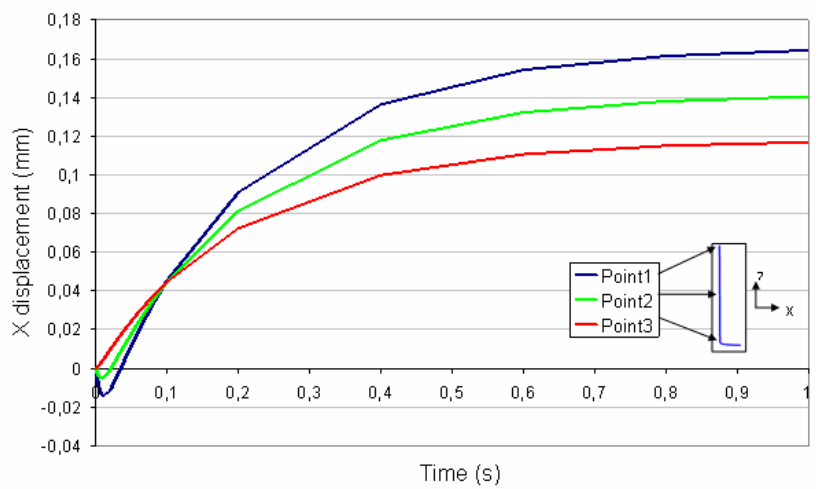

Fig. 8. Displacement along $X$ axis for points $N^{\circ} 1,2$ and 3

In a general way, these values do not really correspond to a distortion, but rather to an isotropic volume variation, due to the shrinkage of the material.

We can however observe a little distortion at the beginning of quenching. The cause of this distortion is situated at the level of the elbow. We observe a quite small asymmetry of the thermal gradient at this level. The shrinkage of the material is more important on the outside skin, what implies a light opening of the clip. This difference grows until approximately $15 \mathrm{~ms}$ then stabilizes, before decreasing with the stabilization of the temperature in $370^{\circ} \mathrm{C}$.

The phenomenon of shrinkage of the material remains the main cause of the variation of $\mathrm{d} 2$. The distortions observed can modify in the tenth of millimetres this variation, but cannot explain the distortions rose in tests. It lets think that the hypothesis of the distortions generated only during the quenching maybe too strong, and that the heating must be considered.

\subsection{Modellisation of heating}

The result of quenching simulation incites us to be interested in heating operation.

To limit the calculation time, we have to limit the number of finite elements. We use then a model in "flat deformations". This one leans on several strong 
hypotheses but allows a first numerical approach.

On following both figures 9, without and with consideration of the residual stresses of bending, we can notice the influence of the phenomenon of stresses relaxation on distortions.

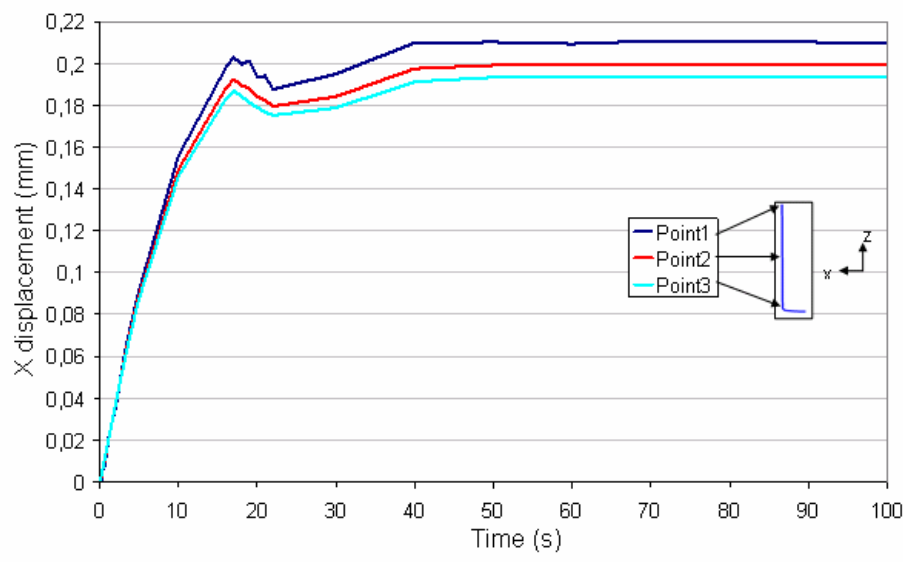

(a)

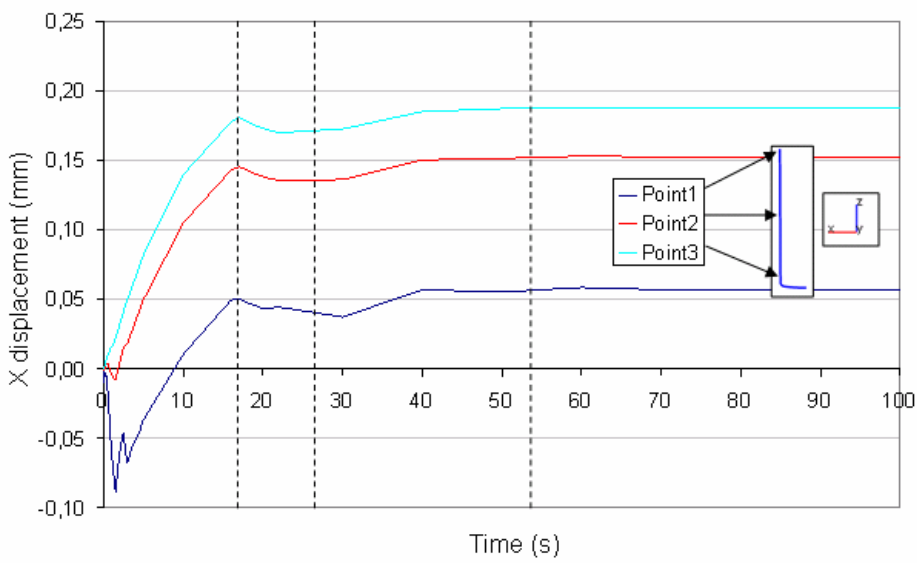

(b)

Fig. 9. Displacement along $X$ axis for points $\mathrm{N}^{\circ} 1,2$ and 3 during heating without (a) and with (b) consideration of the residual stresses of bending

The distortions observed through this numerical model are not representative quantitatively of real distortions, because of the used hypotheses: they remain weak with regard to the laboratory tests of heat treatment.

But the simulations allowed us to identify a source of distortions during the heating: the stresses relaxation.

\section{CONCLUSIONS}

The study on the heat treatment of clips allows us to observe various mechanical, thermal and metallurgical phenomena. The complexity of this problem does not allow us to establish yet a numerical model approaching experimental results. On the other hand, various sources of distortions are able to be revealing thanks to this model.

The first results show a small influence of the operation of quenching. On the contrary, we can see during the heating, that the thermomecanical behaviour of our material is responsible for some distortions. Thanks to hot stretching tests, we are able to model these evolutions and simulate the heating stage. We observe then the influence on distortions of the relaxation of bending residual stresses. In more, the heating is known as a very sensitive operation to the process conditions ...

Nowadays, it seems indispensable to take into account process conditions during heating. What is the impact of the conditions of manufacturing on the distortions with regard to the physical phenomena until then studied?

A study "sensibility process conditions" in first approach will be done. It will allow us to estimate the influence of the process conditions on these distortions, through a numerical approach: studies of the fluage of a single clip according to its position in the furnace and of the fluage of "piled" clips.

\section{ACKNOWLEDGEMENTS}

The authors gratefully acknowledge support from French companies working with the CETIM about the Professional Commission of Fixations.

\section{REFERENCES}

1. F. Herrbach, Modelisation d'un procédé de fabrication d'agrafes, Mastère Mecanique numerique, Centre de Mise en Forme des Matériaux, Sophia Antipolis (2007)

2. C. Aliaga, Simulation numerique par éléments finis en $3 D$ du comportement thermomécanique au cours de traitement thermique d'acier : application à la trempe de pieces forgées ou coulees, Thèse de doctorat, Ecole des Mines de Paris (2000) 